\title{
Accelerating Post-Harvest Food Loss Reduction in Nigeria Through the Development of a Pilot-Scale Vacuum Cooling and Storage System
}

\author{
Jubril Abu Al-Amin ${ }^{1}$ Suleiman A. I. ${ }^{2} \quad$ Eriakha Ehis Collins ${ }^{2}$ \\ 1.Department of Electrical Electronics Technology, School of Engineering, Auchi Polytechnic, Auchi, Edo \\ State, Nigeria \\ 2.Department of Agricultural and Bioenvironmental Engineering Technology, School of Engineering, Auchi \\ Polytechnic, Auchi, Edo State, Nigeria
}

\begin{abstract}
The problem of the loss of food after harvest has drawn worldwide attention in the latest decades. The Food and Agriculture Organization (FAO) and other national and international organizations had estimated that one-third of all foods produced and half of all fruit and vegetables are lost or wasted between harvest and use. In September 2015, the United Nations (UN) announced its objective of decreasing global food waste and significantly decreasing global food loss by 2030, as part of its Sustainable Development Goals (SDG). The post-harvest loss of food is a major challenge in sub-Saharan African nations for farmers and growers, with spoilt foods leading to up to $50 \%$ of harvested food that does not reach the marketplace. This is not only a problem for farmers themselves, who are suffering from decreased incomes and loss of commercial opportunities, but it is also a problem for the environment and resources as far as unnecessary emissions of greenhouse gas are concerned. This paper examines the opportunities that a vacuum storage system presents in reducing food losses after harvest and highlights the challenges in Nigeria to adopt this technology. The equally encapsulated the design, fabrication and testing of vacuum cooling machine
\end{abstract}

Keywords: Postharvest, Food Loss, Nigeria, Storage, Vacuum-Cooling

DOI: $10.7176 / \mathrm{JBAH} / 11-20-03$

Publication date:October $31^{\text {st }} 2021$

\subsection{Introduction}

Sub-Saharan Africa governments have become increasingly worried about the worldwide food crisis in the last two decades. While the prime cause of this crisis is the increase in overall prices of food and other related goods that began in 2006 and has continued to rise. These issues continue for several reasons, including the current greater market-clearing price levels, the continuing price volatility and the erratic food shortages that continue to occur far into the future. (World Bank, 2011). The small-income countries of Sub-Saharan Africa (SSA) have their persistent causative factors, along with persistently low productivity, challenges in acclimatizing climate change, economic challenges presented by their reluctance to address the burden of high food or energy prices, and increased dependence on foreign food aid (World Bank, 2011). However, there is a greater, usually forgotten factor that worsens food insecurity, which is postharvest losses (Bolarin \& Bosa, 2015; Sibanda, 2013).

Agriculture remains a veritable sector that could drive the economic development of Nigeria (Alonge, 2011). Despite the enormous economic opportunities and potentials in the agricultural sector, Nigeria like its other counterparts in Sub-Saharan Africa (SSA) experiences food losses (especially from fresh agricultural produce) during the post-harvest season. In September 2015, as part of its Sustainable Development Goals (SDG), the United Nations (UN) announced its goal of reducing worldwide food waste and considerably reducing worldwide food loss by 2030 (Kitinoja et al., 2011; World Bank, 2011).

Post-harvest loss of food is a serious challenge in Sub-Saharan African countries with spoiled food resulting in $50 \%$ of harvested food not entering the marketplace (FAO, 2019). This is not only a concern for farmers themselves who are suffering from lower profits and loss of business opportunities, but it is also a problem for the environment and resources regarding excessive greenhouse gas emissions. To mitigate these challenges, the adoption of a vacuum cooling technology that is potentially powered by a renewable energy source (Solar PV) will solve these problems. With available technologies for cooling being capital intensive requiring grid electricity is relatively expensive. There is a need to design a vacuum cooling system to reduce post-harvest fruits and vegetable losses (Suleiman A.I., Atanda E.O., Ajayi. S., and Chanchangi Y.N., 2019).

Vacuum cooling is accomplished under vacuum conditions by evaporating part of the moisture of the fresh agricultural produce. The main feature of vacuum cooling is that the fresh produce can be cooled at extremely high speed, which is not surpassed by other conventional methods of cooling (Suleiman et al, 2019). To evaluate the effectiveness and viability of the solar-powered vacuum cooling systems for commercialization, the air temperature and relative humidity efficiency of the vacuum cooling system was monitored and evaluated throughout the cooling and storage. 
Assessment of fruits and vegetable quality and their shelf life was equally be obtained and compared to other fruits and vegetables controlled by conventional means. Selected fruits such as mangoes, oranges, bananas, pineapples, guava, watermelon were used as sample fruit from the experimental plots, while carrots, tomatoes, cabbage, cucumber and spinach were used respectively as root and leaf vegetables. Fruits or vegetables from the various geographical fields will also be collected. Variance analysis (ANOVA) was used to check for any important relative humidity and temperature differences. The predicted outcome was enhanced understanding of renewable energy source(solar) driven vacuum cooling system, enhanced knowledge of vacuum cooling psychometrics, enhanced knowledge of air dynamics/flow within the system. The results will also provide a description of the application of pre-packaging and the appropriate packaging to be used together with the cooling system. Owing to the use of the vacuum cooling system, the shelf-life of fruits and vegetables were improved, minimizing post-harvest losses. This will translate into sustainable fruits and vegetable growth, allowing smallscale farmers and emerging farmers to enter the export market.

In the tropical and subtropical areas, most of Sub-Saharan Africa's emerging economies generate a significant part of food, such as fruit and vegetation (Kitinoja et al., 2018). It is critical for food entering the supply chain to be precoated or cooled to the optimal temperature instantly after harvest that has the greatest opportunity of longlife shelf life (Sibanda, 2013). This is particularly important where ambient temperatures are high (Bolarin \& Bosa, 2015). A one-hour delay in removing field heat from produce harvested at about $35^{\circ} \mathrm{C}$ can lead to a one-day reduction in shelf life (Bolarin \& Bosa, 2015). After-harvest cooling technology is accessible but usually depends on the electricity grid or diesel generator. The provision of alternative off-grid solutions is vital in a region in which 1.2 billion individuals, mostly rural, do not access reliable grid-based electricity. In developing economies of SSA, diesel generators are especially problematic because of high expenses, unreliable fuel production and fuel price volatility as well as their potential environmental impact through greenhouse gases and other emissions. This is an unsustainable alternative. (Sibanda, 2013).

\subsection{An Overview of Post-Harvest Losses in Sub-Sahara Africa}

Most sub-Saharan African (SSA) economies are driven by agriculture (Ingrao et al., 2016), This is the case of the Republic of South Africa (RSA), where an estimated $20 \%$ of the population, estimated at 50 million people, depend directly or indirectly on agriculture for employment and living (Sibanda, 2013). In the RSA industry, marketable food produce yields approximately $3 \%$ of gross national product and approximately $7 \%$ of official jobs (Sibanda, 2013). In SSA, the crops cultivated in tropical and subtropical environments consist of field and horticultural crops, fruit and vegetables such as grapes, oranges, lemons, apples, avocados and mangoes and vegetables including potatoes, tomatoes, onions and cabbages. (Sibanda, 2013; World Bank, 2011). Ever since, attention has been moved to producing SSA cereal crops for food safety and reducing post-harvest losses affecting these plants as documented by World Bank (2011), at the cost of fresh produce.

Post-harvest loss accounts for actual physical losses and quality losses that decrease the crop's economic value or render it unfit for human consumption. In extreme instances, these losses can account for up to 80 per cent of total output (World Bank, 2011). Post-harvest losses across the African continent were estimated to range from $20 \%$ to $40 \%$, which is considerably large given the low agricultural productivity in several continent territories. According to the World Bank Report (2011), sub-Saharan Africa alone loses food grains worth about USD 4 billion every year.

With the current rise in urban customer demand for fruit and vegetables, attention has shifted to the production of fresh produce in many SSA nations (Sibanda, 2013; World Bank, 2011). This is more so since small-scale farmers in SSA nations achieve maximum fresh produce yields than other crops (Tesfaye and Tirivayi, 2018). Research on post-harvest technology measures in the production of fresh produce in SSA is now a study concern, according to Sibanda (2013), considering the incidence of food losses during harvest. Most food losses result during harvesting, handling, and transportation; when agricultural products are packaged, processed, and stored.

According to Mijinyawa as cited in Sibanda (2013), a study conducted in some communities in Nigeria on post-harvest food losses indicated that as much as $20-30 \%$ of total grain production, $30-50 \%$ of root and tuber, and generally a large proportion of fruits and vegetables are lost with significant quantities reported during storage (Sibanda, 2013). In the perspective of this, losses after harvest have resulted in the country's food shortages. Unless issues associated with post-harvest losses are avoided, the main aim of the United Nations (UN) on international food safety would not be achieved (Bolarin et al.,2015).

The greatest challenge in the cultivation of new crops in tropical and subtropical climates in SSA fields is maintaining optimum conditions during storage and transport to markets (Bolarin and Bosa, 2015; Sibanda, 2013). Fruit and vegetables have a high moisture content which makes them susceptible to spoilage, thus decreasing their shelf life (Kitinoja et al., 2018). This metabolism and senescence according to Sibanda (2013), is impaired by adverse environmental variables after harvesting, some fresh produce continues to transpire and ripen after harvesting. Consequently, product preservation after harvest is key to reducing postharvest losses which are estimated at a world average of over 30\% (Kitinoja et al., 2018; World Bank, 2011). 


\subsection{Recent Estimations and Target for Post-Harvest Reduction Losses in Sub-Saharan Africa (SSA)}

The SSA territory is strategic for international food security and with the human population expected to reach 9.1 billion by 2050 , and around $70 \%$ of the additional food needed to feed them, postharvest loss issues are one that needs urgent and practical solutions (Agrihouse Foundation, 2018). Post-harvest food losses reduction technologies are a sustainable solution for increasing food accessibility, reducing pressure on natural resources, eliminating hunger, and improving the livelihoods of farmers. Fruit and vegetables in Tanzania contributed US\$ 120 million to GDP, while horticultural exports in Zambia amounted to US\$ 36 million in 2004 (Sibanda, 2013). Fruit exports from Mozambique to South Africa are worth US\$ 20 million annually (Sibanda, 2013). South Africa estimated gross export earnings in deciduous fruits in 2002 was estimated at R8.1 billion (Sibanda, 2013).

Indigenous farm practices have shown that vegetables and fruits production increase the financial status of farmers, i.e. health and earnings (World Bank, 2011). There has been a boom in fruit and vegetable production in several SSA nations, including mangoes, bananas, citrus, avocado, papaya, pineapple, passion fruit, grapefruit, grapefruit, grape, apple, pear, guava, strawberry and plum, tomatoes, cabbages, onions, sweet pepper, chillies, okra, garlic, ginger, carrot, lettuce, spinach and other leafy vegetables (Sibanda, 2013). Fruit and vegetables are traded and consumed fresh while others are used in the processing factories, primarily producing fruit juices and fruit juice concentrates.

Interest in the reduction of postharvest food losses is not new. According to the World Bank (2011), after the food crisis in the mid-1970s, substantial investment in postharvest technologies was made in reducing the loss of food after harvest(Tesfaye \& Tirivayi, 2018; World Bank, 2011). Actually, in 1975, the United Nations brought the world's attention to post-harvest storage losses by declaring that further reduction of post-harvest food losses in developing nations should be undertaken as a priority (World Bank, 2011). Poor implementation of post-harvest loss techniques promoted in different SSA nations has also resulted in decreasing investment in this area (Porat et al., 2018).

In Ghana, where crop harvesting is primarily done manually using hand cutting tools, inadequate handling is readily one of the fields that deserve immediate attention if food security is to be attained (Agrihouse Foundation, 2018). A 2016 study by the Africa Post Harvest Losses Information System discovered that, during the postharvest period, the nation loses about 318,514 tons of maize per year. In these areas, maize, sorghum, rice, groundnut, cowpea and vegetables are the main crops that are often impacted by perennial post-harvest losses.

With a renewed focus on agriculture and following the latest food and financial crises, the incidence of postharvest food losses has been significantly raised. Post-harvest food loss reduction interventions are a significant component of many agencies ' attempts to decrease SSA food insecurity (Tesfaye and Tirivayi, 2018; World Bank, 2011). Post-harvest losses are increasingly acknowledged as part of an integrated strategy to realize the complete opportunity of agriculture to satisfy the growing food and energy requirements of the world. Reducing post-harvest losses through efficient and effective techniques is therefore critical to the challenge of feeding an enhanced world population (World Bank, 2011). In latest worldwide projects such as the Comprehensive Framework for Action published in 2009 by the UN High-Level Task Force on Food Security and Nutrition following the global food crisis, the World Bank's Global Agriculture and Food Security Program approved in January 2010, and the lately established Committee on World Food Security posited that post-harvest losses are prominent. (World Bank, 2011).

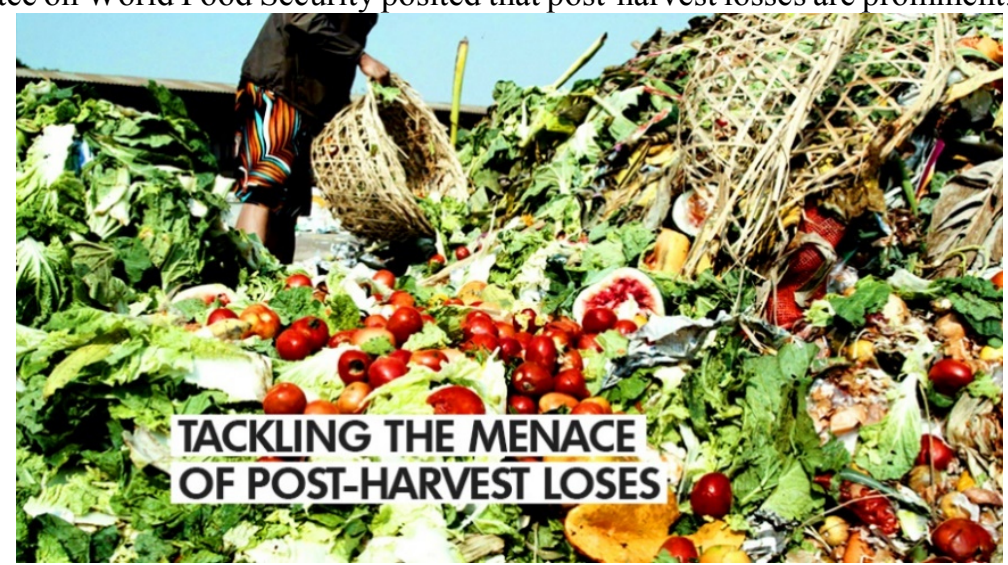

Figure 1: Tackling the Menace of Post-Harvest Loses

Source: (Agrihouse Foundation, 2018)

\subsection{Conceptualisation of the research project}

Attention in the past has been paid to the production of cereal crops in SSA for food security and the reduction of postharvest losses affecting crops as reported by World Bank (2011), at the expense of fresh produce. With the recent change in consumer demand for urban fruits and vegetables, the focus has shifted to the growth of 
fresh produce in many African countries (Workneh, 2007; Altman et al., 2009). This is more so since smallscale farmers in African countries get higher yields from fresh produce compared to other crops. The greatest challenge in the production of fresh produce in tropical and subtropical areas up to marketing is to sustain optimum conditions during storage and transport to markets (Sibanda, 2013). Fruits and vegetables have a high content of moisture that makes them susceptible to spoilage and thus increasing their shelf life (Workneh, 2007).

Therefore, it is necessary to ensure that a substantial percentage of this enters both domestic and international markets in a fresh and appealing state. This can only be ensured if optimal temperature and relative humidity storage conditions are maintained Therefore, this research was carried out to develop technologies such as vacuum cooling systems that maintain optimal storage conditions. Research on appropriate cold chain technology is a problem to farmers in Nigeria as the existing refrigeration system is expensive and has high energy demands, hence the need came to develop this technology that will have low energy requirements and can be used off-grid, particularly in areas where the farms are located in remote areas.

\subsection{Objectives of the Research}

The primary aim of the research was to design, fabricate and test a pilot-scale vacuum cooling system that uses solar energy to operate a water pump and fan to circulate air in the cooling and storage unit during fruits and vegetables postharvest operations. FAO estimates from the year 2011 indicates that between production and consumption, as much as 37 percent of food produced in sub-Saharan Africa is lost (World Bank) due to improper preservation and storage of produce. The FAO figure is only $8 \%$ for post-harvest handling and processing losses, and the African Post-harvest Losses Information System (APHLIS) estimate is 10-12\% (World Bank 2011). In sub-Saharan African countries, the farming communities incur tremendous post-harvest losses annually (Kitinoja et al., 2011). As a result, it is important to pay attention to this fact to ensure that both small and large-scale farmers are profitable and that end-users have enough fresh produce (Sibanda, 2013). Because of their perishability factor, tropical and subtropical fruits and vegetables such as tomatoes, carrots and spinach have been found to have storage and transport problems (Megan Sheahan. and Barrett C. B., 2017).

\subsection{Vacuum Cooling Storage System}

Many cooling technologies have been developed over the years, including evaporative cooling, vacuum cooling, hydro-cooling and forced air cooling(Sibanda, 2013; Venu et al., 2017). Usually, SSA small scale farmers have not adopted any of the storage techniques because of their costs. Farm owners cooling systems in either advanced nations or large-scale SSA business farms are not suitable for small-scale farmers and are not linked to the energy grid (Sibanda, 2013). The fact is that most of the SSA-owned farms are not linked to the electricity grid.

The use of a vacuum storage system as a suitable cooling technology is being developed as a palliative to these energy and storage problems. This is because it is becoming cheaper because of the price of energy from renewable energy sources and small-scale farmers can afford this storage system as a cooperative organization or as a key storage system for the commodity board or market (Sibanda, 2013). The vacuum storage system does not necessarily use grid electricity but adopts to be operational using alternative renewable energy sources such as solar energy, biomass and wind power. That is, they can be used as off-grid systems. Most of the post-harvest losses for fruit and vegetables, particularly in SSA, are largely due to the absence of adequate storage equipment.

As stated previously, there are popular mechanisms for preserving fresh vegetables and fruit shortly after harvest, which include mechanical cooling, hydro-cooling, evaporative cooling, cold room cooling, forced air cooling and vacuum cooling (Sibanda, 2013). These techniques of cooling attempt to preserve the quality of fresh produce in the state of harvesting. The vacuum cooling system that has evolved using renewable energy as its power source is prominent among these techniques.

Vacuum cooling is a swift evaporative cooling technology aimed at specific cooling requirements for porous and moist foods (Sibanda, 2013; Venu et al, 2017). It is achieved through surface and product moisture evaporation. Evaporation is activated and made more effective by lowering the pressure to the point where water is boiled at low temperatures. The distinction between vacuum cooling and conventional cooling is that by blowing cold air or another cold medium over the product, the vacuum cooling impact is accomplished (Sibanda 2013). The two primary characteristics of vacuum cooling are velocity and effectiveness, unmatched by any standard technique of cooling, especially when cooling boxed or palletised materials (Sibanda, 2013). Vacuum cooling is effective in terms of energy as it only removes heat from products. The cooling time is set at 30 minutes to enable the rigorous cooling criteria to guarantee that food safety and quality are met.

Any product with free water and the composition which will not be destroyed when such water is removed can be cooled in a vacuum. The velocity and efficiency of vacuum cooling are primarily linked to the proportion of its evaporation surface to the product mass (Affognon et al, 2015; Sibanda, 2013). Fresh products with greater transpiration rates, such as lettuce, sweet corn, celery and sprouted beans, have been noted to do well with vacuum cooling (Sibanda, 2013). However, the use of Solar Photo Voltaic (PV) as a power source in vacuum cooling is 
advanced in the bid to decrease or eliminate electricity costs from the use of fossil fuels.

\subsection{Vacuum Cooling Storage System: The Way Forward}

With increasing energy efficiency emphasis, the need to reduce the $\mathrm{CO}_{2}$ footprint and boost demand for cooling systems has prompted farmers to look for new storage techniques. The kinds of solar-based structures presently being considered are using solar photovoltaic cells' electrical power to operate standard cooling systems and convert solar thermal energy into electricity. To preserve quality and decrease losses, fruit and vegetables require adequate storage and management after harvest. The primary cause of post-harvest losses in the SSA is the susceptibility of perishable crops during storage and transport. If delicate and perishable products such as fruits and vegetables can reach the market without delay and associated rough handling, the unpleasant statistics resulting from post-harvest losses could well be upgraded shortly. (Sibanda, 2013). To achieve this, it would require the use of a vacuum cooling storage system.

Again, it is a known issue that postharvest losses are accelerated at higher temperatures and poor storage technologies (Sibanda, 2013; Stathers, 2017). The emergence of renewable energy precooling storage facilities could help hold and preserve perishable goods until transportation means are brought in to move the goods to the market. A good storage facility like the vacuum cooling storage facility that is solar powered could preserve this produce at cheaper rates since the cost of energy is low or zero. A significant number of crops in developing countries are lost after harvest, leading to hunger and resulting in expensive inputs such as fertilizer, irrigation water, and human labour being wasted (Agrihouse Foundation, 2018).

The second Sustainable Development Goal (SDG) focuses on ensuring that food is available that leads to zero hunger. Post-harvest techniques to reduce food losses must play a key role in achieving this result. Using post-harvest storage techniques such as the storage system like vacuum cooling is a valuable instrument during this era to reduce food losses. This storage technology enhanced by renewable energy technology would enable farmers to have more to sell at a competitive price while improving the livelihood of rural populations. A list of selected agricultural products that can be preserved is shown in Table 1 below.

Table 1: Optimum storage temperatures in ${ }^{0} \mathrm{C}$ for selected crops (Sibanda, 2013)

Products

Broccoli

Optimum Temperature $\left({ }^{0} \mathrm{C}\right)$

Cabbage

Lettuce

Carrots

Tomatoes

Potatoes

0

Onions

Garlic

Cucumber

5-15

$1-2$

Spinach

10-13

Oranges

0

Oranges

$0-2$

Avocado pear (ripe)

$0-2$

$3-7$

Strawberry

$1-5$

Papaya

There is no indication that the implementation of temperature control cooling systems to achieve optimum recommended temperatures for fresh produce depends on the production scale (Sibanda, 2013; Venu et al., 2017). Hence, the main reason large-scale farmers adopt these techniques such as vacuum cooling storage. Due to economies of scale, small-scale farmers in SSA are left out. SSA small-scale farmers now have restricted access to these cooling techniques, if any, and this is mainly due to cost. The cost and technical knowledge of these techniques generate the gap and fresh produce is therefore stored and transferred at ambient temperature(Sibanda, 2013).

The need to close this gap between large-scale and small-scale farmers sets priorities for studies to develop a solar-powered, low-carbon or zero-carbon cooling technology based on existing expertise, adaptability, suitability, and environmentally sustainability. This solar-powered storage technology will effectively tackle the problem of increasing loss of fresh produce as it helps small-scale farmers ensure that they have a facility they can set for each commodity at the optimum temperature.

\subsection{Fruits and Vegetable Business in Africa}

There is a growing demand for fresh fruits and vegetables in Africa with recent changes in consumer demand 
(Garcia and Barret, 2004). The sub-sector is characterized by varying farm size heterogeneity ranging from largescale producers with significant investments in irrigation, agricultural inputs and professional management to small-scale farmers usually below 0.5 ha.

African experience in the agricultural sector has shown that fruits and vegetable production enhance the living conditions of farmers in terms of nutrition and income (Bourne, 1977; Workneh, 2007 \& 2010). This has seen several Sub-Saharan African countries increasing their production of fruits such as mangoes, bananas, citrus, avocado, papaya, pineapple, passion fruits, grape, apple, pear, guava, strawberry and peach. Vegetables include tomatoes, cabbages, onions, sweet pepper, cowpea, lentil, leek, chillies, okra, garlic, ginger, carrot, turnip, mushroom, asparagus, cucurbits, lettuce, spinach and other local leafy vegetables. Fruits and vegetables are traded and consumed fresh while others are used in processing plants, producing mainly fruits juices and distilled fruits juice.

\subsection{Postharvest Losses}

Fruits and vegetables post-harvest losses require proper post-harvest management to maintain quality and reduce losses. Throughout storage and distribution, the vulnerability of perishable produce is the main cause of postharvest losses in Africa's tropical and subtropical regions. Azene et al., (2011) argued that post-harvest losses may deter farmers from venturing into fresh produce production and marketing, thus affecting the supply side of urban fruits and vegetable consumption. Therefore, reducing post-harvest losses would be of great importance to farmers and consumers alike, particularly if it can be avoided economically (Johnson and Sangchote, 1994).

In 2011, the United Nations Food and Agriculture Organization (FAO) announced annual food losses in SSA that reached 30 percent of total crop production, reflecting an annual cost of more than US\$ 4 billion (World Bank, 2011). During the World Food Program (WFP) Action Research Review, it was alarming to note that these loss rates rose to much higher levels as farmers stored crops for periods longer than 4 weeks. Such annual food losses, even at the lower estimate, far outweigh the total amount of international food aid provided to SSA countries every year (Megan Sheahan. and Barrett C. B., 2017).

\section{Causes of Postharvest Losses}

Postharvest losses result from several factors including environmental, biological and chemical and technological factors. Fruits and vegetables are also influenced by environmental factors such as temperature, relative humidity and gas composition. Many fruits and vegetables have more than 80 percent moisture content (Jain, 2007) and high respiration levels (Workneh, 2007; Caleb et al., 2011).

Fruits and vegetables compositions are also delicate and do not withstand extreme environmental and impact conditions. Technical factors resulting in post-harvest losses include mechanical/physical damage caused by improper handling (Adeoye et al., 2009; Vigneault et al., 2009; Basediya et al., 2011) or lack of skill in the use of suitable equipment designed to maintain optimum perishable product conditions. Physiological and biological processes cause water evaporation resulting in chemical and physical fruit and vegetable changes (Brosnan and Sun, 2001; Pathare et al., 2012). Fresh produce also has injuries caused by temperature extremes, i.e. both extremely high and low (Vigneault et al., 2009). Various fruits and vegetables have different tolerance levels to temperature extremes, and this is more so when considering cool processing (Kader, 2010; Prusky, 2011). Table 2.1 shows the vulnerability of fruits and vegetables to chilling injury at low but non-freezing temperatures. The first commercial vacuum cooler was installed in 1948 for precooling iceberg lettuce, to remove field heat after harvest and to prolong product shelf-life (Lijun Wang and Da-Wen Sun, 2001). Subsequently, its application was broadened to other agricultural produce such as mushrooms, cabbage, celery, and cauliflower, among others (Lijun Wang and Da-Wen Sun, 2001). The rapid cooling times have stirred interest in other sectors of the food industry (e.g., bakery, fishery, sauces, particulate foods, etc.) (McDonald and Sun, 2000; Lijun Wang and Da-Wen Sun, 2001).

More recently, the integration of vacuum-cooling into the processing procedures of prepared consumer foods such as cooked meats and ready meals (e.g., meat pies and pasta dishes) has widened the application of this technology in line with increasing demands from consumers for safe and high-quality products, and from the food industry and regulatory bodies for rapid cooling methods that meet food safety guidelines and speed up processing times (Lijun Wang and Da-Wen Sun, 2001). Table 2.2 showcases the different cooling technologies for extending the shelf life of fresh produce.

\subsection{Principles of Operation of a Vacuum Cooling Technology}

Vacuum cooling involves reducing pressure inside a sealed chamber. The water inside the vegetables turns to vapour, absorbing heat energy. The principle of vacuum cooling is based on a portion of the produce moisture under vacuum is rapidly evaporated. The boiling point of water is lower under pressure, resulting in the evaporation of dispensable water. The greater the temperature of the atmosphere, the lower becomes the boiling point of steam. The water on the surface of the cooled materials evaporates continuously during the process of creating the vacuum. 
The evaporation cycle quickly and efficiently extracts heat from the materials. It also does not harm cooled products and can retain the original sensor and taste. Figure 1 below shows a typical vacuum cooling process for production.

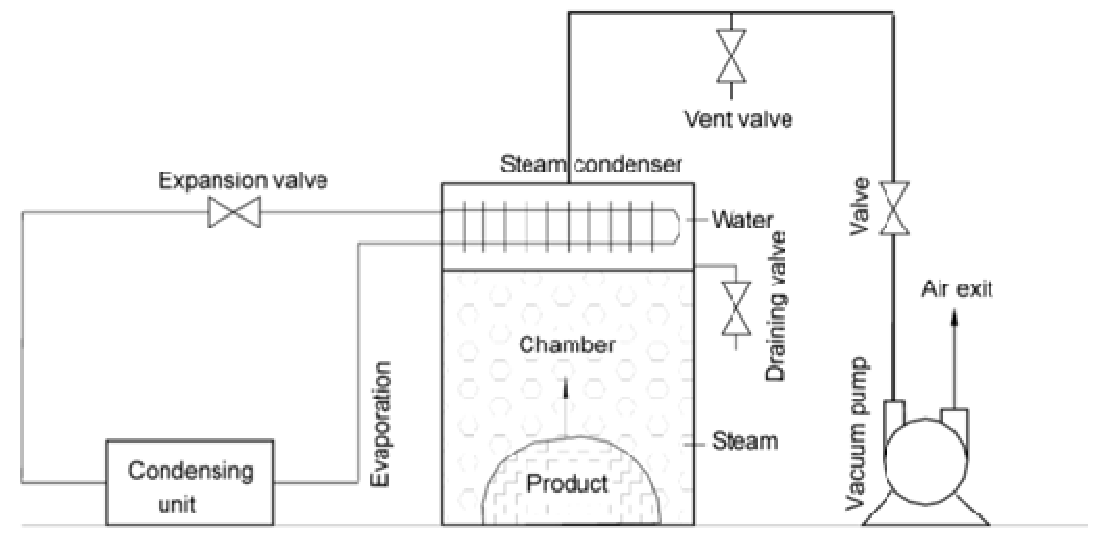

Figure 1: A Typical Vacuum Cooling Machine for a produce Source: Lijun Wang and Da-Wen Sun, 2011

In 20-30 minutes, leaf vegetables can be cooled without pressure from 25 to $35^{\circ} \mathrm{C}$. With food produce that easily loses water such as lettuce, carrots, mushrooms, onions, tomatoes and cabbage plants (Ayobami O. O., and Haile M and Wenjuan Q. and Cunshan Z., and Bengang W, 2017; Lijun Wang and Da-Wen Sun, 2001), vacuum cooling works best. It is estimated that $1 \%$ of the product weight is turned into water vapour for every $5^{\circ} \mathrm{C}$ drop in temperature. A typical chart of a Vacuum cooling process for broccoli produce is as shown in figure 2.

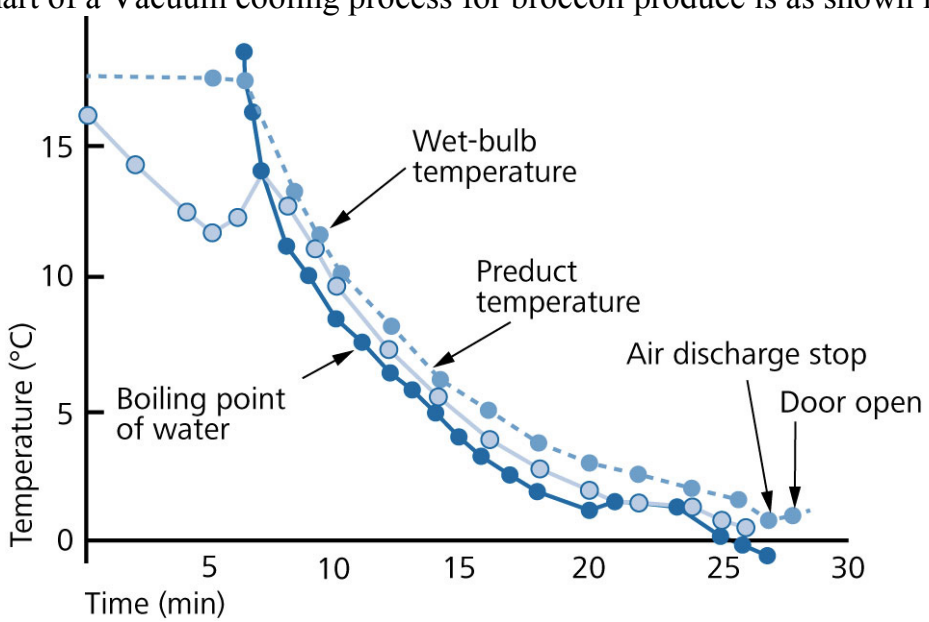

Figure 2: A Typical Chart of a Vacuum Cooling Process for Broccoli

Source: Huaxian, 2019

This method of cooling is equally suitable for high surface-weight produce such as leaf lettuce, pumpkin, cucumber, spinach, mushrooms, sprouts and more compact products such as green beans, broccoli, celery and maize. From the core of the produce, vacuum cooling works, extending its shelf life and processing time. In addition, it makes exporting the products to foreign markets simpler. It can be used to reduce processing times, increase the shelf life of the products and boost produce quality and safety. Traditionally, in the agricultural industry, vacuum cooling is used to pre-cool leafy vegetables and mushrooms so that field heat can be quickly removed. Any product that has free water and the composition of which is not affected by removing such water can be cooled in a vacuum. Vacuum cooling's rate and efficacy are primarily related to the ratio between its evaporation surface area and food mass (Lijun Wang and Da-Wen Sun, 2001). Table 2.4 describes the actual heat and the estimated decrease in temperature caused by the percentage weight loss per unit for pure water and certain standard foods (McDonald \& Sun 2000; Sweat, 1994; Lijun Wang and Da-Wen Sun, 2001). 
Table 2.1 Vulnerability of fruits and vegetables to chilling injury at low but non-freezing temperatures Commodity Minimum safe Chilling injury symptoms References temp. ${ }^{\circ} \mathrm{C}$

\begin{tabular}{|c|c|c|c|}
\hline Avocados & $5-13$ & Grey discolouration of the flesh & $\begin{array}{l}\text { Campbell et al., } 1960 \\
\text { florinssen et al., } 1996\end{array}$ \\
\hline Bananas (green/ripe) & $12-14$ & Dull, grey-brown skin colour & Murata, 1969 \\
\hline Beans (green) & 7 & Pitting, russeting & Watada and Morris, 1956 \\
\hline Cucumbers & 7 & Pitting water-soaked spots, decay & Lutz and Hardenburg, 1966 \\
\hline Grapefruits & 10 & $\begin{array}{l}\text { Brown scald, piking, watery } \\
\text { breakdown }\end{array}$ & Lutz and Hardenburg, 1966 \\
\hline Mangoes & $10-13$ & Grey skin scald, uneven ripening & Lyons, 1973 \\
\hline Oranges & 7 & $\begin{array}{l}\text { Pitting brown stain, watery } \\
\text { breakdown }\end{array}$ & Eaks, 1960 \\
\hline Papaya & 7 & $\begin{array}{l}\text { Pitting failure to ripen, off-flavour, } \\
\text { decay }\end{array}$ & FAO, 1989 \\
\hline Potatoes & 4 & Internal discolouration, sweetening & Lutz and Hardenburg, 1966 \\
\hline Pumpkins & 10 & Decay & FAO, 1989 \\
\hline Sweet potato & 13 & $\begin{array}{l}\text { Internal discolouration, piking, } \\
\text { decay }\end{array}$ & Lyons, 1973 \\
\hline $\begin{array}{l}\text { Tomatoes: } \\
\text { green }\end{array}$ & 13 & Watery soaked softening, decay & Salve, 1991 \\
\hline
\end{tabular}
Source: Sibanda, 2013

Table 2.2 Comparison of different cooling technologies in terms of temperature and relative humidity and extension of shelf life of fresh produce.

\begin{tabular}{|c|c|c|c|}
\hline Commodity & $\begin{array}{l}\text { Minimum safe } \\
\text { temp. }{ }^{\circ} \mathrm{C}\end{array}$ & Chilling injury symptoms & References \\
\hline Avocados & $5-13$ & Grey discolouration of the flesh & $\begin{array}{l}\text { Campbell et al., } 1960 \\
\text { florinssen et al., } 1996\end{array}$ \\
\hline $\begin{array}{l}\text { Bananas } \\
\text { (green/ripe) }\end{array}$ & $12-14$ & Dull, grey-brown skin colour & Murata, 1969 \\
\hline Beans (green) & 7 & Pitting, russeting & Watada and Morris, 1956 \\
\hline Cucumbers & 7 & Pitting water-soaked spots, decay & Lutz and Hardenburg, 1966 \\
\hline Grapefruits & 10 & Brown scald, piking, watery breakdown & Lutz and Hardenburg, 1966 \\
\hline Mangoes & $10-13$ & Grey skin scald, uneven ripening & Lyons, 1973 \\
\hline Oranges & 7 & Pitting brown stain, watery breakdown & Eaks, 1960 \\
\hline Papaya & 7 & $\begin{array}{l}\text { Pitting failure to ripen, off-flavour, } \\
\text { decay }\end{array}$ & FAO, 1989 \\
\hline Potatoes & 4 & Internal discolouration, sweetening & Lutz and Hardenburg, 1966 \\
\hline Pumpkin & 10 & Decay & FAO, 1989 \\
\hline Sweet potato & 13 & Internal discolouration, picking, decay & Lyons, 1973 \\
\hline $\begin{array}{l}\text { Tomatoes: } \\
\text { mature green }\end{array}$ & 13 & Watery soaked softening, decay & Salveit, 1991 \\
\hline \multicolumn{4}{|c|}{ Source: Lijun Wang and Da-Wen Sun, 2001} \\
\hline \multicolumn{4}{|c|}{$\begin{array}{l}\text { Table 2.3 Moisture Content, specific heat and temperature decrease per unit of percentage weight loss } \\
\text { for pure water and some typical foods }\end{array}$} \\
\hline & Mo & ture $(\%) \quad c\left(k J / \mathrm{kg}^{\circ} \mathrm{C}\right)$ & $\eta \mathrm{T}\left({ }^{0} \mathrm{C} / \mathbf{1} \%\right.$ weight loss $)$ \\
\hline Water & & 4.2 & 6 \\
\hline Leafy vegetables & & 90 & 6.5 \\
\hline Cooked meats & & 3.5 & 7 \\
\hline B & & 35 & \\
\hline ked foods & & & .5 \\
\hline Water & & 100 & 6 \\
\hline
\end{tabular}


products, cooked meat and ready meals and fish tuna. Depending on storage and shipping periods, different internal and final temperatures are needed, a cooling temperature of $5^{\circ} \mathrm{C}$ or higher is appropriate for short time and distance, whereas longer processing times and long distances need a temperature of less than $1^{\circ} \mathrm{C}$.

\subsection{Design Concepts}

The methodology adopted included:

a. Design and fabrication of the vacuum cooling system with the potential of solar PV installation. The vacuum cooling system's theoretical design method was considered; water circulation system, air circulation, mechanism of storage/transportation, relative humidity and temperature control system.

b. The theoretical design was translated into the real design used for the construction of the pilot scale system.

\subsubsection{Fabrication and Installation of the Vacuum Cooling System}

This process included: (a) Allocation of a fabricator to fabricate the vacuum chambers and accessories (b) monitoring the fabrication process to ensure conformity to appropriate working standards.

\section{C: Testing the System}

1. Evaluation of the air temperature and relative humidity efficiency of the vacuum cooling system was monitored and evaluated throughout the preservation and storage periods.

2. Assessment of fruits and vegetable quality and their shelf life was obtained and compared to other fruits and vegetables controlled by conventional means. Selected fruits such as mangoes, bananas, citrus, avocado, papaya, pineapple, passion fruits, grape, apple, pear, guava, strawberry and peach were used as sample fruit from the experimental plots while carrots, cabbage, cucumber, onions, ginger, pumpkin, watermelon and spinach were used respectively as root and leaf vegetables.

3. Fruits or vegetables from the various geographical fields will also be collected. Variance analysis (ANOVA) was used to check for any important relative humidity and temperature differences.

4. The fabricated storage system was installed in the Agricultural Bioenvironmental Engineering laboratory at Auchi Polytechnic for performance evaluation.

5. The cooling performance was evaluated using fruits and vegetables.

6. The proximate analysis, physicochemical properties of the stored fruits were done after storage for one, two, three months respectively.

\subsubsection{Design process}

A theoretical design of the vacuum cooling system considering (i) water circulation system (ii) air circulation from vacuum pumping system (iii) storage/transportation with the aid of the technology (iv) relative humidity and temperature control system and (v) modelling and optimization of tilt angle for solar vacuum cooling system for the selected location was established. The theoretical design was translated to the actual design that was used for the construction vacuum cooling technology.

The temperature decrease caused by per unit of percentage weight loss would be determined mathematically by the equation:

$$
\eta_{T}=\frac{\Delta T}{\Delta \quad M W / m_{p}}=\frac{h_{f g}}{c}
$$

Equation 1

Source: Andrew, 1963

As shown in the equation above, the specific food heat defines the percentage weight loss temperature decrease per unit.

There are two components in the pumping process which are the vacuum pump and a vapour condenser. The vacuum pump is normally designed to reduce the pressure in the vacuum chamber from the atmospheric pressure to the saturation pressure at the initial food temperature for 3-10 minutes (Longmore, 1973). For a vacuum cooler, the rotary oil-sealed vacuum pump is commonly chosen. One can calculate the appropriate pumping speed $\left(\mathrm{m}^{3} / \mathrm{h}\right)$ by (Andrew, 1963; Lijun Wang and Da-Wen Sun, 2001):

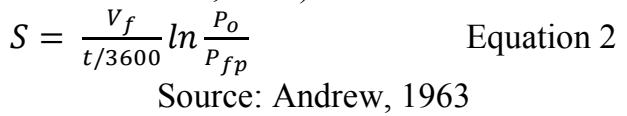

In addition, the vapour condenser acts as a vacuum pump for extracting the vapour in the vacuum chamber by condensing the vapour back into water and then filtering out the liquid. It should be remembered, however, that the cooling effect of food comes from the evaporation of water in foods, and the use of a vapour condenser in a vacuum cooler is only for the practical and economical removal of a large amount of vapour produced.

The maximum evaporated water during the cooling vacuum of food products can be computed by (Rennie, Raghavan, Vigneault, \& Gariepy, 1999; Lijun Wang and Da-Wen Sun, 2001). 


$$
\Delta_{m_{w}}=\frac{c m_{p} \Delta T}{h_{f g}} \quad \begin{gathered}
\text { Equation 3 } \\
\text { Source: Rennie et al., 1999 }
\end{gathered}
$$

\section{Theoretical design}

The following factors were determined:

(i) The vacuum cooling system capacities are dependent on farmers requirements.

(ii) The cooling load was included to calculate the field heat of fresh produce at harvest and the respiratory heat production were used in designing for the cooling load.

(iii) The ventilation rate $\left(\mathrm{m}^{3} / \mathrm{s}\right)$ helped to determine and to select the right fan size. The cooling pad size will influence the amount of water circulating per unit time. The amount of water circulating per unit time will help determine the pump size.

(iv) The proximate analysis, physicochemical properties of the stored fruits were done after storage for one, two, three months respectively.

\subsection{Construction and Fabrication of the Solar-Powered Vacuum Cooling System}

Fabrication of the vacuum cooling system would be carried out using mild steel sheets, iron, pipes and fittings to accommodate a one-tonne capacity chamber for selected fresh produce (usually two pallets). The pilot-scale size system was replicated in another location where the research analysis would equally be covered. The Vacuum Cooling system was installed with the off-the-shelf vacuum pump, refrigeration compressor, air compressor, condition fans, reducer, and electrical box controller. It is estimated that eighty (80) Solar Panels with $310 \mathrm{KW}$ capacity each in modules and arrays were used as the primary electricity source with the inverters and batteries as accessories. The figure below shows our proposed layout of the solar-powered vacuum cooling system.

\subsection{Results and Discussion \\ 4.1 Testing of the Vacuum Cooling Machine}

The Vacuum Cooling system air temperature and relative humidity were tested and monitored throughout the storage period. The relative humidity of an air-water vapour mixture was determined using psychometric charts. Both the dry-bulb temperature $(\mathrm{T})$ and the wet-bulb temperature (Tw) was recorded using a data recorder. The temperature was recorded using psychrometer units attached to thermocouples located in the vacuum cooling system and outside the system to measure ambient temperature. Both temperature and relative humidity were measured across several days.

\subsection{Assessment of quality and Experimental design of the System}

Assessment of fruits and vegetable quality and their shelf life was obtained and compared to other fruits and vegetables controlled by conventional or traditional means (Ayobami et al, 2017). Selected fruits such as tomatoes were used as a sample fruit from the experimental plots, while carrots, cabbage, cucumber and spinach were used respectively as root and leaf vegetables. Fruits or vegetables from the various geographical fields were also be collected. Variance analysis (ANOVA) was used to check for any important relative humidity and temperature differences. The fabricated storage system will be installed in the Agricultural Engineering Laboratory of the Department of Agricultural and Bioenvironmental Engineering at Auchi Polytechnic for performance evaluation. The cooling performance was evaluated using fruits and vegetables. The proximate analysis, physicochemical properties of the stored fruits were done after storage for one, two, three months respectively.

\subsection{Conclusion}

Reducing food losses after harvest is a very effective way to increase food accessibility and ensure food security in SSA. The advantages of using the vacuum storage system include 400 percent longer shelf life, enhanced product quality and demand, additional export opportunities, decreased water and energy waste, decreased $\mathrm{CO} 2$ emissions by up to 65 percent, and lower power duty on the remainder of the cold chain - lower operating cold storage expenses. Solving post-harvest food losses and transport through this vacuum cooling storage system would involve collaboration and efficient communication between all involved research extension officers and industry personnel. It is also vital to overcome the socio-economic limitations caused by technical knowledge and installation costs to achieve the objective of decreasing post-harvest food losses using the vacuum cooling storage system. Conclusively, the decrease to the minimum of post-harvest food losses remains of extreme significance for the realization and support of the Nigerian and Africa Governments and international food security. No doubt from the test carried out so far this machine requires further evaluation before its adoption for commercial purposes.

\subsection{Recommendation}

To develop at a quicker rate and further reinforce the postharvest industry in Nigeria, some of the recommendations 
for adopting this technology may include; the creation of community-specific supply chains and the gradual integration of other small supply chains in the Nigerian region, utilization of railway network, creation of front end infrastructure for undeveloped markets, promotion of research through public-private partnership for commercialisation and further development of this technology. The use of the rail network will advance the vacuum cooling technology through; the development of front-end infrastructure for undeveloped markets, advancement of research through public-private development partnerships and further advancement of this technology.

\section{Acknowledgements}

This work was funded by the Institution Based Research Grant of Tertiary Education Trust Fund (TETFUND) in Nigeria. The researchers appreciate TETFUND and the Management of Auchi Polytechnic for Providing funds for this research.

\section{REFERENCES}

Adeoye, I. B., Odeleye, S. O., Babalola, S. O. and Afolayan, S. O. (2009) "Economic analysis of tomato losses in Ibadan Metropolis, Oyo estate, Nigeria" African Journal of Basic and Applied Sciences 1(5-6): 87-92.

Alonge A. F. (2011). Food Processing, Preservation and Storage for Economic Development in Nigeria: Proceedings of the 11th International Conference and 32nd Annual General Meeting of the Nigerian Institution of Agricultural Engineers (NIAE Ilorin 2011), October 17 - 20, 2011, Ilorin, Nigeria. ISBN: 978036-578-8, Vol. 32: $57-64$

Andrew, G. (1963). Rotary oil-sealed pumps. In Vacuum technology (pp. 49-76). London, UK: John Wiley \& Sons.

Altman, M, Hart, T, and Jacobs, P. (2009) "Food security in South Africa. Centre for poverty and employment and growth" Human Sciences Research Council.

Ayobami Olayemi Oladejo and Haile Ma and Wenjuan Qu and Cunshan Zhou and Bengang Wu, 2017. "Effects of Ultrasound on Mass Transfer Kinetics, Structure, Carotenoid and Vitamin C Content of Osmodehydrated Sweet Potato (Ipomea Batatas)," Food Bioprocess Technol, vol. 10, pp. 1162-1172.

Azene, W, Workneh, T. S, and Woldestadik, K. (2011) "Effect of packaging materials and storage environment on postharvest quality of papaya fruits" Journal of Food Science and Technology. doi:10.1007/s13197-0110607-6.

Backeberg, G. R. (2006) "Reform of user charges, marketing and management of water: problem or opportunity for irrigated agriculture" Irrigation and Drainage 55(1): 112.

Baker, J. E. (1975) "Morphological changes during maturation and senescence. In Postharvest physiology, handling and utilization of tropical and subtropical fruits and vegetables" (Ed ) Pantastico, EB, AVI Publishing, Westport, CT. p 128.

Baloyi, J. K. (2010) "Analysis of constraints facing smallholder farmers in the Agribusiness value chain. A case study of farmers in the Limpopo province. Masters In Agricultural Economics" Thesis. Department of Agricultural Economics, Extension and Rural Development. Faculty of Natural and Agricultural Sciences, University of Pretoria. South Africa.

Basediya, A. L, Samuel, D.V.K, and Beera, V. (2011) Evaporative cooling system for storage of fruits and vegetables - a review. Food Science Technology. DOI 10.1007/s 13197-011-0311-6.

Beckles, D. M. (2012) Factors affecting the postharvest soluble solids and sugar content of tomato (Solanum Lycopersicum L.) fruits. Postharvest Biology and Technology 63:129-140.

Bourne, M. C. (1977) Postharvest losses - the neglected dimension in increasing the world food supply. Cornell Univ Int Agric Mimeogr 53:20-27.

Bourne, P. A. (2009) The implication of utility access on gender: The case of Jamaica. European Journal of Social Sciences 8(4): 614-625.

Brosnan, T, and Sun, D. (2001) Precooling techniques and applications for horticultural products - a review. International Journal of Refrigeration 24(2):154-170.

Caleb, O. J, Opara, U. L, and Witthuhn, C. R. (2011) Modified atmosphere packaging of pomegranate fruits and arils: a review. Food and Bioprocess Technology doi 10.1007/s11947-011-0525-7.

Deepak Kumar and Prasanta Kalita, (2017) "Reducing Postharvest Losses during Storage of Grain Crops to Strengthen Food Security in Developing Countries," MDPI, vol. 6, no. 1, p. 8.

FAO, (2000) Solar photovoltaic for sustainable agriculture and rural development. Environment and natural resource service sustainable development department. Food and Agriculture Organizations of the United Nations Working paper No. 2, Rome.

FAO, (1989) Harvest handling and losses. Food and Agriculture Organizations of the United Nations, Rome. The world vegetable centre. Newsletter. Food and Agriculture Organizations of the United Nations, Rome. www.avrdc.org. 
FAO, (2019) "Food Loss and Food Waste," FAO, 2019. [Online]. Available: http://www.fao.org/food-loss-andfood-waste/en/. [Accessed: 08-Oct-2019].

Focusun, 2019 "Focusun Vacuum Cooler: efficiently cool,”. [Online]. Available: http://www.vacuum-cooler.com/. [Accessed: 09-Oct-2019].

Garcia, E, and Barret, D. (2004) Processing fruits, science and technology. (Eds) Barret, D, Somogyi, L and Ramaswamy, H. CRC Press, Boca Raton Florida, USA. 53

Getinet, H, Workneh, TS, and Woldetsadik, K. (2008) The effect of cultivar, maturity and storage environment on quality of tomatoes. Food engineering 87:467-478.

Huaxian, "Vacuum Cooler/Vacuum Cooling Machine," (2019) [Online]. Available: http://www.huaxianfresh.com/Products/2019_1_384.html. [Accessed: 08-Oct-2019].

James, SJ, and James, C. (2011) Improving energy efficiency within the food cold chain. 11th International Congress on Engineering and Food (ICEF) 22-26 May 2011. Athens, Greece.

Jain, D. (2007) Development and testing of two-stage evaporative cooler. Building and Environment 42: 25492554.

Johnson, GI, and Sangchote, S. (1994) Control of postharvest diseases of tropical fruits: Challenges for the 21 st century. In: Postharvest handling of fruits, ACIAR Proceedings, 50: 140-161.

Kader, A.A. (Ed.) (2010). Postharvest technology of horticultural crops, third ed. Cooperative Extension of University of California, Division of Agriculture and Natural Resources, University of California, Davis, CA, Publication no. 3311.

Lijun Wang and Da-Wen Sun (2001) "Rapid cooling of porous and moisture foods by using vacuum cooling technology," vol. 12, no. 2001, pp. 174-184.

Megan Sheahan. and Barrett C. B., (2017) "Food loss and waste in Sub-Saharan Africa: A critical review," Food Policy Vol 70, no.1, p.1-12.

McDonald, K., and Sun, D.W., (2000) "Effect of vacuum cooling on the thermophysical properties of a cooked beef product" Journal of Food Engineering.

Olosunde, W. A., Aremu, A. K., and Okoko, P. 2016a. Computer simulation of evaporative cooling storage system performance. Agricultural Engineering International: CIGR Journal, 18(4):280-292.

Olosunde, W.A., Aremu, A. K, Onwude, D. I. 2016b. "Development Of A Solar Powered Evaporative Cooling Storage System For Tropical Fruits And Vegetables," Food Process. Preserv. 4, vol. 40, pp. 279-290.

Porat R., Lichter A., Terry L. A., Harker R., and Buzby J., (2018) "Postharvest losses of fruits and vegetables during retail and in consumers' homes: Quantifications, causes, and means of prevention," Postharvest Biology and Technology.

Rennie, T. J., Raghavan, G. S. V., Vigneault, C., \& Gariepy, Y. (1999) "Temperature distribution in vacuum cooled lettuce under varying process parameters" ASAE Paper No. 991080. St. Joseph, MI, USA: American Society of Agricultural Engineering.

Sibanda, S. (2013) "Development of a Wind and Solar Powered Mobile Evaporative Cooling System for Temporary Storage and Transportation of fruits and vegetables" $\mathrm{PhD}$ In Agricultural Engineering Thesis. School of Engineering University of KwaZulu-Natal Pietermaritzburg.

Suleiman A. I., E. O. Atanda, A. S. Ajayi and Y. N. Chanchangi. (2019) "Advancing post-harvest food loss reduction in Sub-Saharan Africa using solar-powered vacuum cooling storage system as a palliative" Conference Proceedings of the Nigerian Institution of Agricultural Engineers, Vol. 40, 2019. September 16th - 20th 2019

Sweat, V. E. (1994) Thermal properties of foods. In M. A. Rao, \& S. S. H. Rizvi (Eds.), Engineering properties of foods (pp. 99-138). New York: Marcel Dekker.

Workneh, T. S. (2007) Present status and prospects of postharvest preservation technology of fresh fruits and vegetables in Ethiopia. Journal of the Ethiopian Society of Chemical Engineers 10(1): 1.

World Bank (2011) Missing food: The Case of Postharvest Grain Losses in Sub-Saharan Africa. https://doi.org/10.1038/ncb2790.Role 


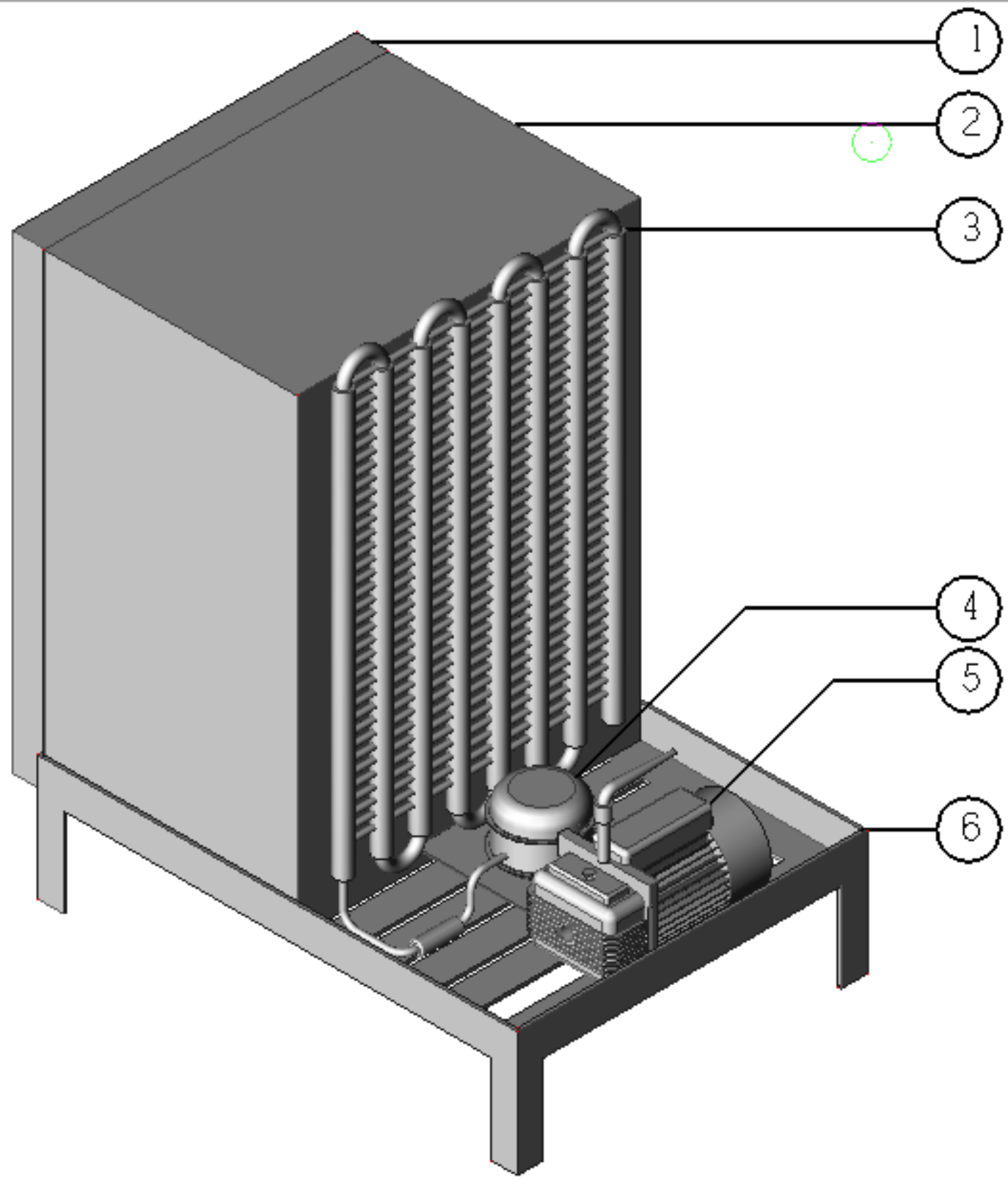

\begin{tabular}{|l|l|}
\hline 1 & DOOR \\
\hline 2 & VACUUM CHAMBER \\
\hline 3 & CONDENSER \\
\hline 4 & VACUUM COMPRESSOR \\
\hline 5 & VACUUM PUMP \\
\hline 6 & VACUUM SYSTEM FRAME \\
\hline ITEMS & DESCRIPTION \\
\hline
\end{tabular}



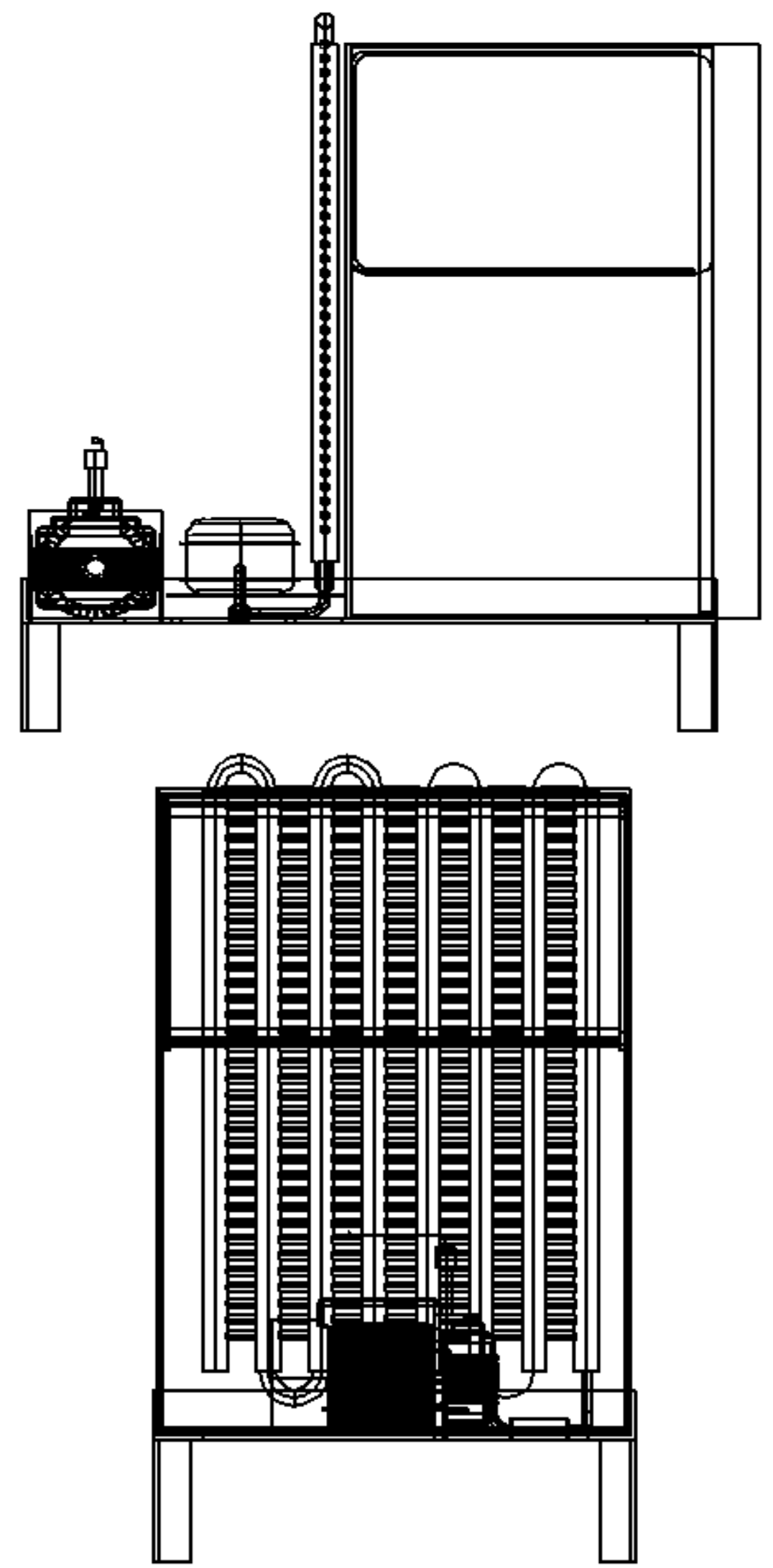

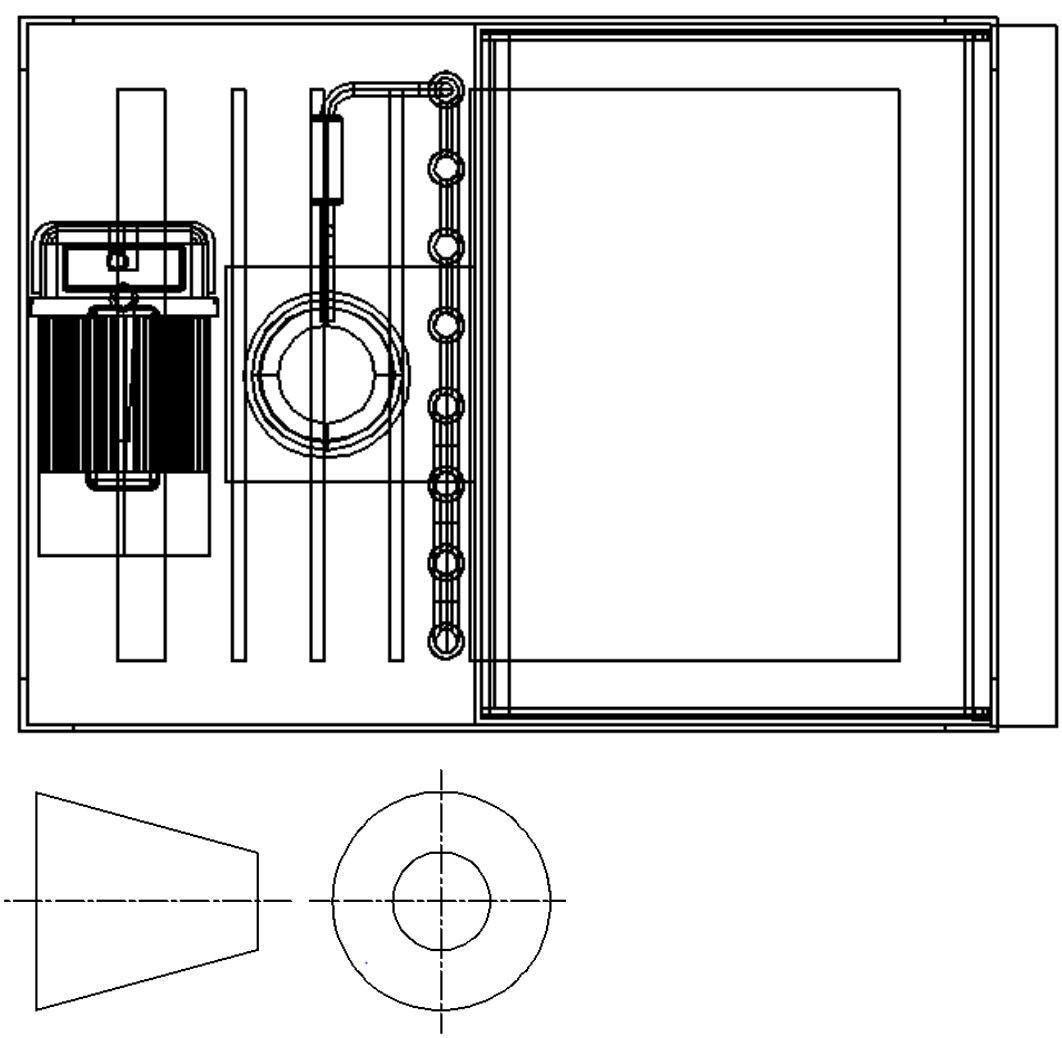


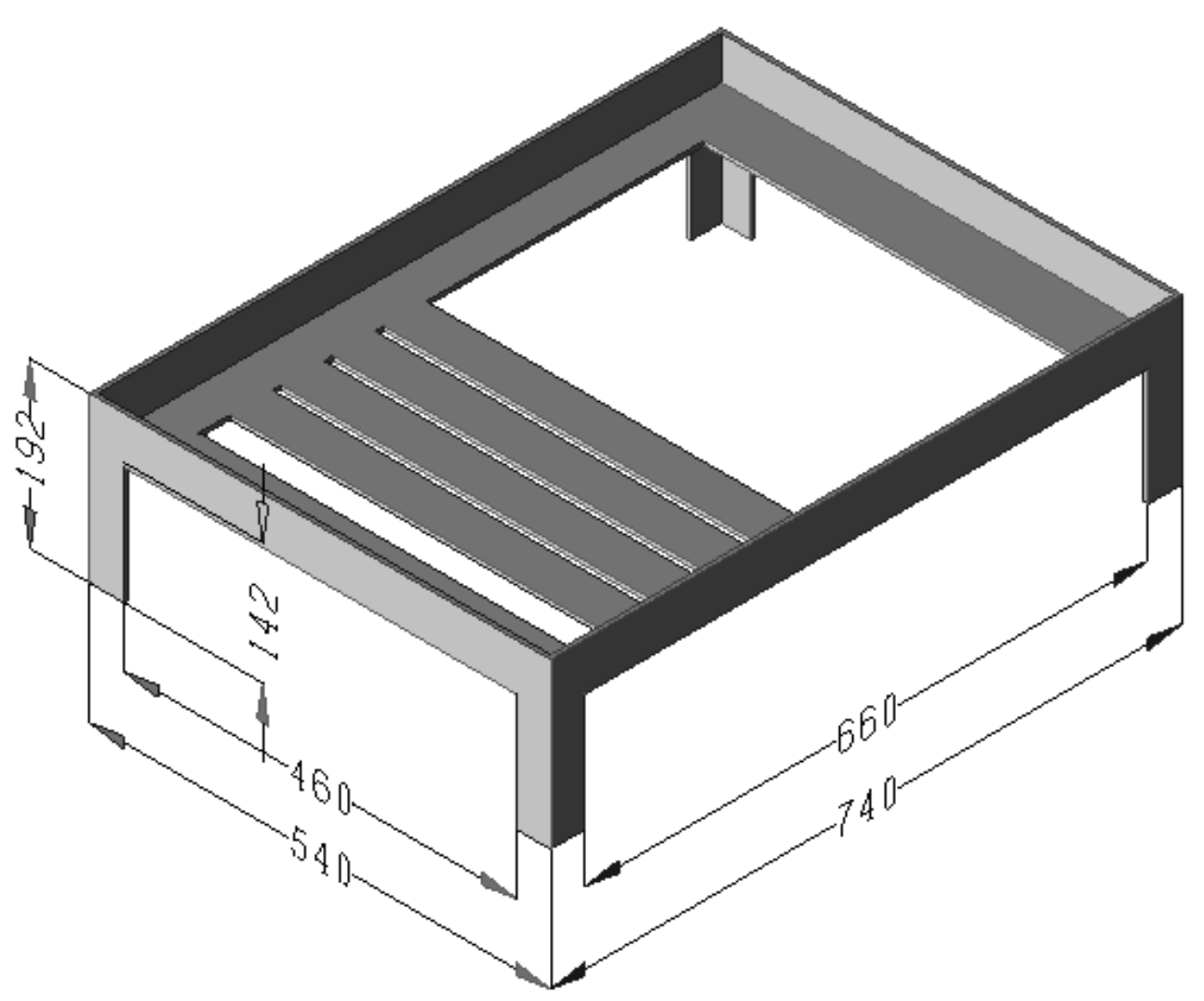




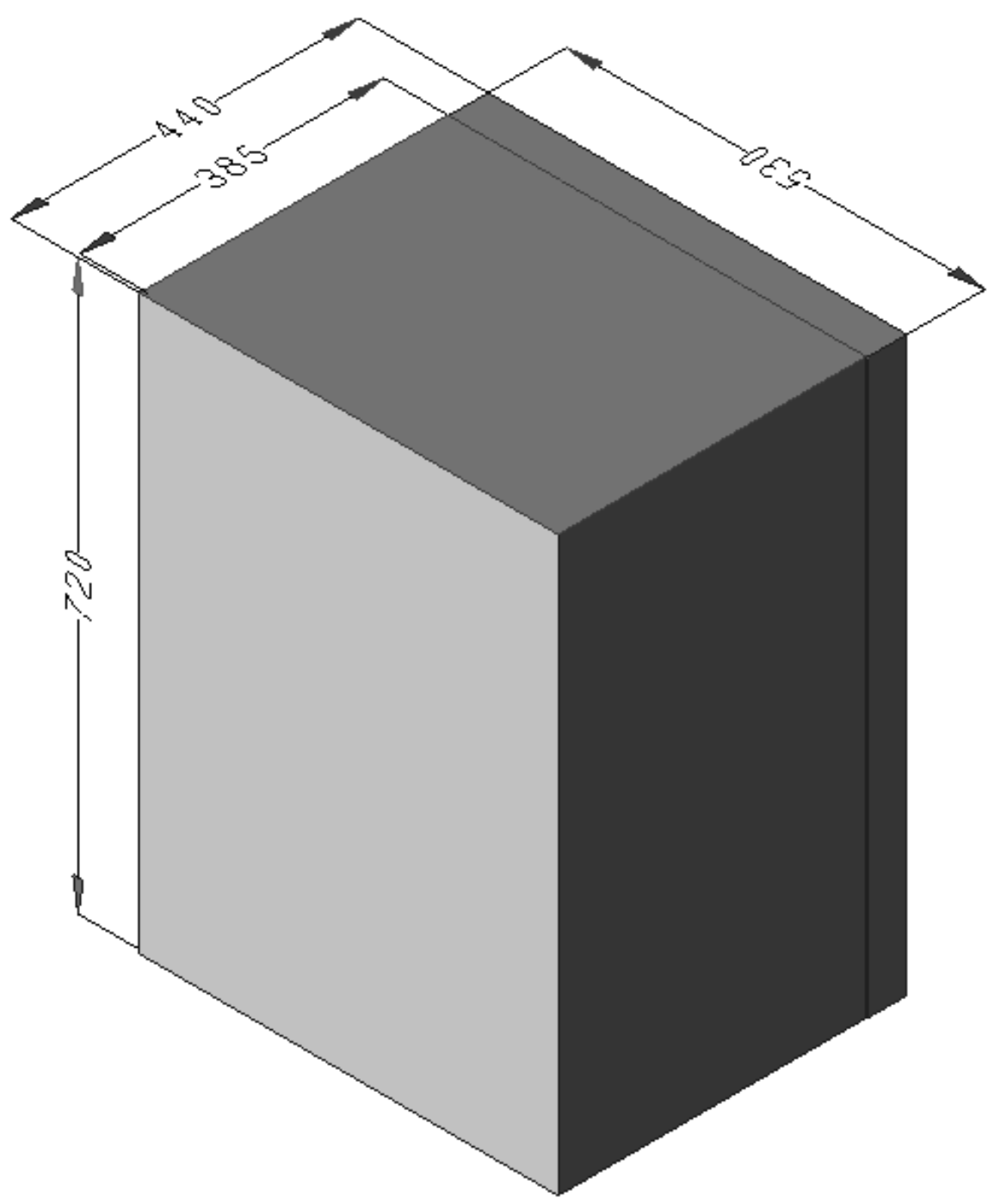



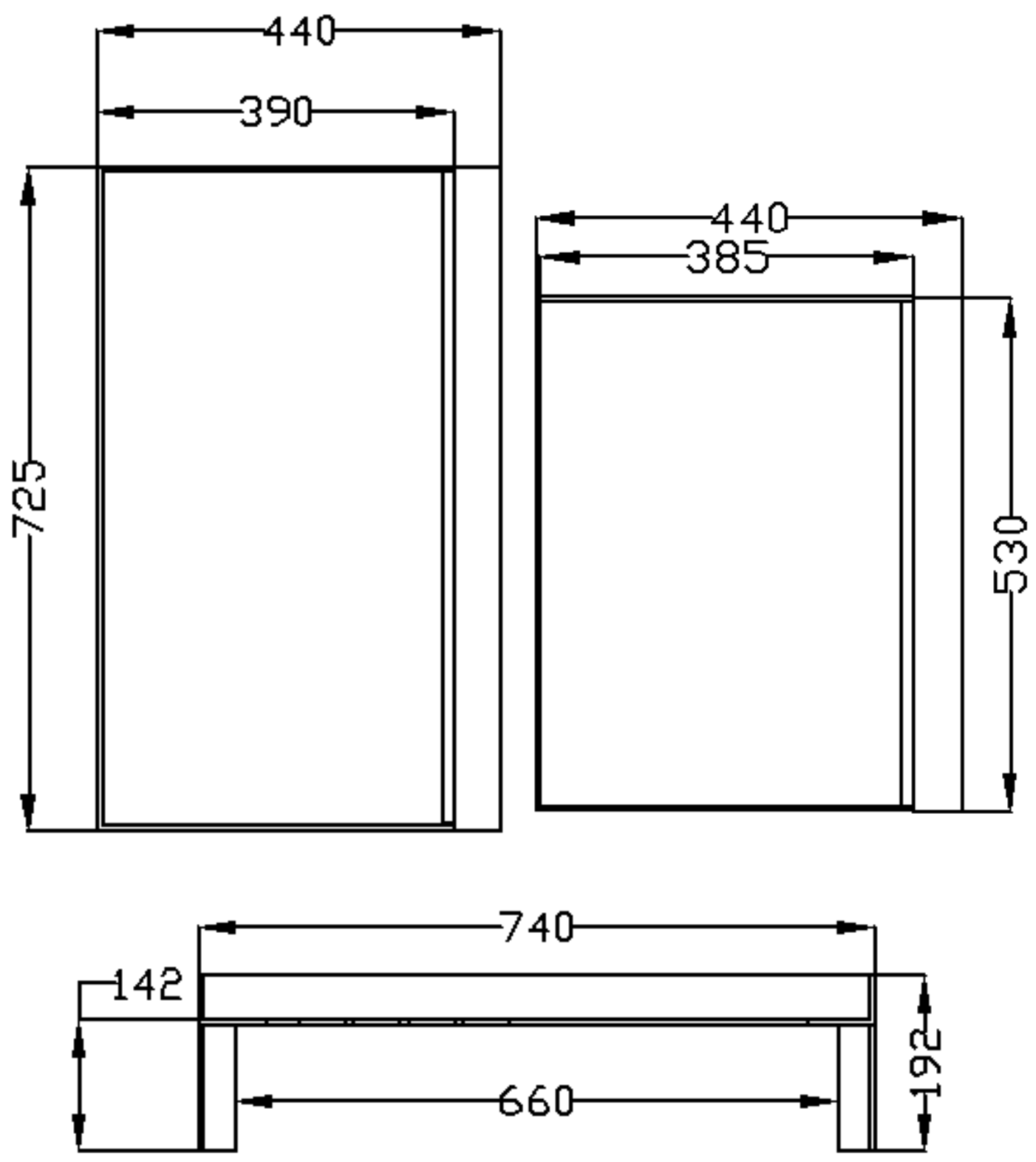


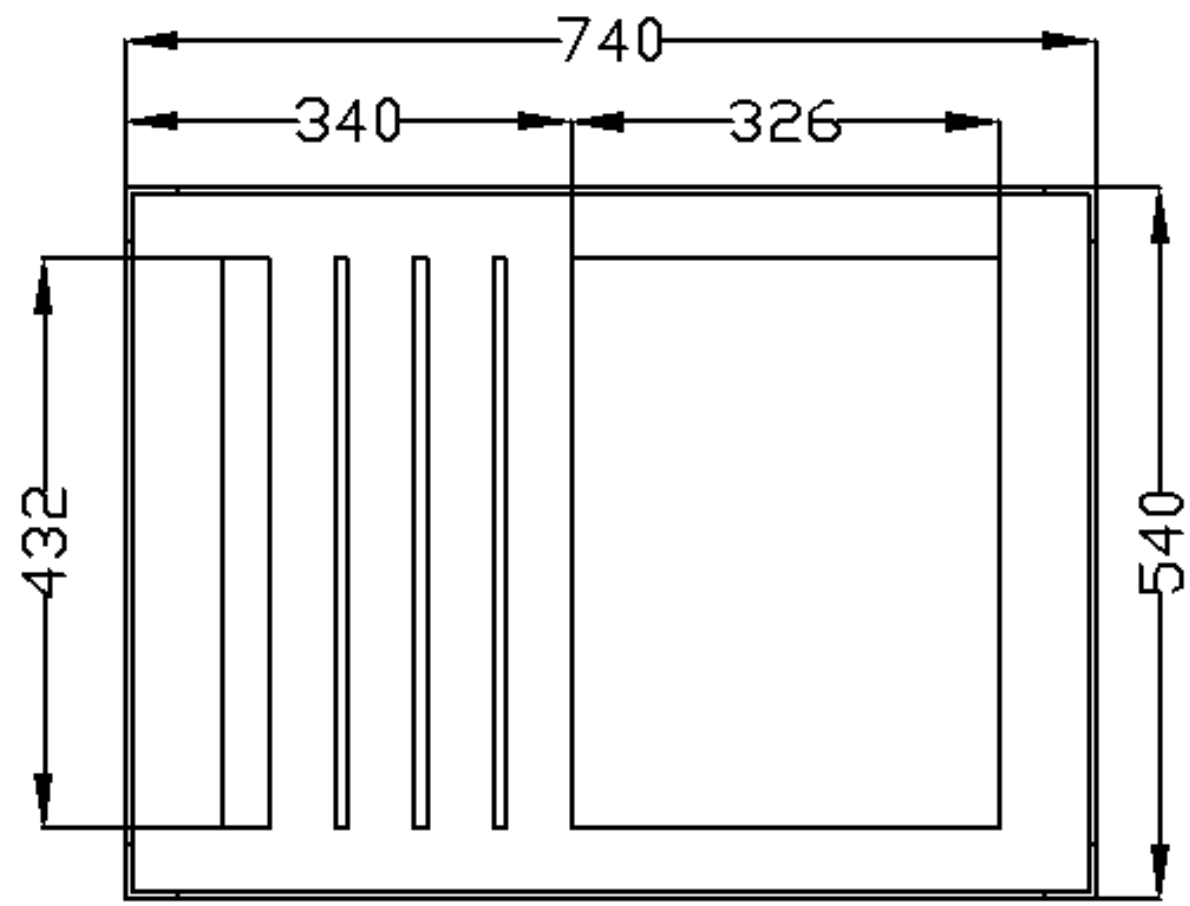

